\title{
PAGAMENTO POR SERVIÇOS AMBIENTAIS (PSA) E PRÁTICAS DE AGRICULTURA SUSTENTÁVEL: CONTRIBUIÇÕES DA ANÁLISE DO COMPORTAMENTO
}

\author{
Thainara Granero de Melo \\ Universidade Federal de São Carlos (UFSCar) \\ Diana Catherin Mercado González \\ Universidade Federal de São Carlos (UFSCar)
}

\section{Resumo}

O Pagamento por Serviços Ambientais (PSA) é uma estratégia utilizada desde o final da década de 1990 para recompensar os serviços ambientais prestados por agricultores, financiando ações de recomposição da vegetação em áreas desmatadas, práticas agrícolas de baixo impacto já desempenhadas, e incentivando para que estes passem a adotar práticas sustentáveis de agricultura. O objetivo deste artigo é conhecer os princípios contidos nas estratégias de PSA para a solução de problemas ambientais, bem como discutir como são implantados na prática, a partir da interpretação analítico-comportamental de uma experiência de PSA na região de Ribeirão Preto, Estado de São Paulo. Reconhece-se os argumentos que validam os ganhos ambientais obtidos, e considera-se a necessidade de problematizar a suficiência dos incentivos financeiros na promoção de mudanças comportamentais e sua manutenção ao longo do tempo.

Palavras-chave: Pagamento por Serviços Ambientais; Políticas Públicas; Agricultura; Desenvolvimento Sustentável; Análise do Comportamento.

\section{PAYMENTS FOR ENVIRONMENTAL SERVICES (PES) AND PRACTICES OF SUSTAINABLE AGRICULTURE: CONTRIBUTIONS FROM BEHAVIOR ANALYSIS}

\begin{abstract}
This paper aims to know the Payment for Environmental Services (PES) principles and its implementation in practice, based on a behavior-analytic interpretation of a PES experience in the State of São Paulo, region of Ribeirão Preto. PES program is a strategy used since the 1990 s to give financial incentives for farmers to provide environmental services. PES is a tool to fund actions of restoration at deforested areas, recognize low-impact practices already performed, and promote the adoption of sustainable practices. The arguments that support environmental gains provided by PES are recognized, but the effectiveness of financial incentives to promote behavior change and its maintenance for long term is questionable.
\end{abstract}

Keywords: Payment for Environmental Services; Public Policies; Agriculture; Sustainable Development; Behavior Analysis. 


\title{
PAGO POR SERVICIOS AMBIENTALES (PSA) Y PRÁCTICAS DE DESARROLLO SOSTENIBLE: CONTRIBUCIONES DEL ANÁLISIS EXPERIMENTAL DEL COMPORTAMIENTO
}

\begin{abstract}
Resumen
El Pago por Servicios Ambientales (PSA) es una estrategia que se viene utilizando desde finales de la década de 1990 para recompensar los servicios ambientales prestados por agricultores, mediante la financiación de acciones de recomposición vegetal en áreas deforestadas, prácticas agrícolas de bajo impacto que ya vienen siendo implementadas, e incentivando la adopción de prácticas de agricultura sustentable. El objetivo de este artículo es reconocer los principios de las estrategias de PSA para la solución de problemas ambientales, y debatir la forma en la que éstas se dan en la práctica, a partir de la interpretación analítico-comportamental de una experiencia de PSA en la región de Ribeirão Preto, Estado de São Paulo, Brasil. Se reconocen los argumentos que certifican los beneficios ambientales alcanzados, pero se considera necesario evaluar la capacidad que tienen los incentivos financieros en la promoción de cambios comportamentales y el mantenimiento de estos en el tiempo.

Palabras clave: Pago por Servicios Ambientales; Políticas Públicas; Agricultura; Desarrollo Sostenible; Análisis Experimental del Comportamiento.
\end{abstract}

\section{INTRODUÇÃO}

As discussões em torno das ameaças causadas pelos impactos ambientais têm estado cada vez mais presente do cotidiano social. Aquecimento global, poluição do ar, escassez de água para o consumo humano e para a produção alimentar, e o desmatamento são apenas alguns dos muitos problemas enfrentados pela sociedade. Em razão de um maior contingente populacional existente nas áreas urbanas, os problemas ambientais parecem se tornar ainda mais evidentes nestes territórios. Mas os riscos e preocupações sobre o desenvolvimento sustentável vão além dos contextos urbanos, sendo também incorporados por pesquisadores e formuladores de políticas públicas para o desenvolvimento rural.

No Brasil, o período conhecido como Revolução Verde, entre as décadas de 1960 e 1970, marcou a mudança no padrão de produção e de consumo dos alimentos, introduziu a produção de monoculturas em larga escala, a utilização de insumos industriais, a mecanização e a exploração extensiva dos solos e dos recursos naturais. Sessenta anos depois, os impactos deste modelo de agricultura são sentidos na atual crise global, alimentar e ambiental. Desde 2010, a Organização das Nações Unidas para a Alimentação e Agricultura (Food and Agriculture Organization of the United Nations, FAO) e o Banco Mundial alertam para o risco de aumento da fome no mundo, considerando que pelo menos 22 países já enfrentam situação de crise alimentar, a despeito do aumento da produção mundial de alimentos, a qual seria capaz de abastecer todo o contingente populacional (FAO, 2014). Já que o problema do descompasso entre oferta e demanda não está na quantidade de alimentos produzidos, os órgãos apontam como um dos motivos os problemas ambientais, provocados inclusive pela adoção deste padrão tecnológico de agricultura que é 
altamente dependente do consumo de água e de energia para a utilização de agroquímicos, maquinários e transporte.

Com exceção dos desastres naturais, tais como terremotos e furacões, o grande desafio ao se enfrentar as crises ambientais decorre do fato de que são problemas provocados, majoritariamente, por comportamentos humanos (Medeiros \& Haydu, 2013). Assim, ainda que os governos estejam empenhados em propor inovações e estratégias para resolvê-los, seu sucesso depende sobretudo, entre outros fatores, da aceitação e das mudanças comportamentais da população.

O Pagamento por Serviços Ambientais (PSA) tem sido uma estratégia utilizada desde o final de década de 1990 por países latino-americanos para o financiamento da conservação ambiental. Apoiada por agências multilaterais internacionais, como o Banco Mundial, o PSA determina a compensação financeira pelos serviços ambientais prestados por agricultores. O princípio central desta estratégia concentra-se no fato de que o produtor que colabora com práticas sustentáveis e que preserva o meio ambiente deve ser gratificado por seus serviços, ao passo que aquele que recebe por estes benefícios, no caso a população, possa pagar por este serviço por meio de recursos públicos. Dentre as diferentes estratégias existentes no PSA, há tanto a compensação financeira para a recomposição da vegetação em áreas desmatadas, como a valorização financeira de práticas agrícolas de baixo impacto já desempenhadas pelos agricultores, ou ainda, o incentivo para que passem a adotar práticas sustentáveis (Pagiola \& Platais, 2002).

Seriam os incentivos financeiros suficientes para promover mudanças comportamentais e sustentá-las ao longo do tempo? À medida que os incentivos são reduzidos ou interrompidos, a motivação dos indivíduos para se engajar nestes comportamentos manter-se-ia em longo prazo? A Análise do Comportamento é uma das correntes teóricas que tem contribuído para o estudo do comportamento humano a partir da descrição das contingências comportamentais que têm consequências para o conjunto da sociedade e da cultura. Nesta perspectiva, o comportamento é entendido como resultado do processo de interação do organismo com seu ambiente, o que permite o desenvolvimento de um repertório comportamental que tem como estímulo antecedente ou consequente o comportamento de outro organismo, selecionado pelas consequências que ele produz. Dessa forma, é possível verificar os termos e construtos teóricos da Análise do Comportamento no conjunto da sociedade, incluindo-se as políticas públicas e os problemas ambientais.

O objetivo deste artigo é conhecer os princípios contidos nas estratégias de Pagamento por Serviços Ambientais (PSA) para a solução de problemas ambientais, bem como discutir como são implantados na prática, a partir da interpretação analítico-comportamental de uma experiência de PSA na região de Ribeirão Preto, Estado de São Paulo. 
O artigo se encontra dividido em três partes, nas quais serão apresentadas: (1) os principais conceitos propostos pela Análise do Comportamento para compreender o modo como os comportamentos sociais e seus efeitos acumulados interferem nos problemas ambientais, os estudos que investigaram mecanismos de estabelecimento de comportamentos próambientais por estratégias de recompensas financeiras e não financeiras, e estudos que avaliaram as diferentes abordagens de PSA, suas limitações e possibilidades em relação aos problemas ambientais; (2) as estratégias metodológicas adotadas para o estudo; e (3) os resultados e a discussão do caso estudado sobre a recente tradução do PSA em política pública pelo Estado de São Paulo, o PDRS Microbacias II, e as possíveis interpretações analíticocomportamentais sobre esta experiência.

A interpretação analítico-comportamental para os comportamentos sociais e os problemas ambientais

A Análise do Comportamento é uma das correntes teóricas que tem se dedicado a estudar o comportamento humano enquanto produto de um conjunto de três níveis de contingências de seleção, a saber: (a) que garante a sobrevivência do indivíduo por meio da seleção natural; (b) que reforça os repertórios comportamentais adquiridos pelos indivíduos; e (c) que compõe um sistema especial mantido por um ambiente cultural (Skinner, 1981).

Mas, o que significa falar em bem comum? Skinner analisava esta questão como sendo a ação em favor da evolução e da sobrevivência da cultura, quando os comportamentos selecionados são aqueles que têm efeitos sobre o grupo, e não aqueles que são reforçadores apenas para os indivíduos.

Skinner preocupava-se com uma ciência do comportamento que fosse capaz não só de identificar a ação seletiva do ambiente nos diferentes níveis ao produzir problemas individuais e sociais (como a violência, a fome e a educação), mas também de propor soluções - para esses problemas - baseadas em práticas culturais (Holpert, 2004). Por definição, práticas culturais são os comportamentos mantidos pelo grupo por padrões similares de conteúdo comportamental e transmitidos ao longo das gerações por meio de processos de aprendizagem (Sampaio \& Andery, 2010).

O estudo dos fenômenos sociais foi inaugurado por Skinner (1948), a partir da publicação de Walden II, seu livro de ficção científica no qual ilustra uma sociedade utópica e, neste contexto, o papel predominante da ciência. Desde aquela época, o cenário contemporâneo ocidental de estímulo ao consumo já se delineava, criando condições para a seleção dos comportamentos cujas consequências são individuais e imediatas, em detrimento de comportamentos benéficos para o grupo, mas com consequências atrasadas - o que dificultava entender a magnitude do problema. Esta relação pode ser interpretada como um problema de autocontrole: a resposta de autocontrole é uma alternativa às 
respostas impulsivas, que são aquelas que produzem reforçadores mais imediatos, mas de menor magnitude. Assim, diante uma situação de escolha, a resposta selecionada produz reforçadores de maior magnitude, mas de maior atraso. Por isso, o problema do autocontrole é de ordem temporal, quando o indivíduo não se comporta de modo a aguardar uma consequência atrasada e produzir um efeito reforçador, de longo prazo, para a sociedade (Hanna \& Todorov, 2002).

De igual modo, as agências controladoras (Skinner, 1979) têm papel fundamental no estabelecimento do controle sobre os comportamentos individuais e grupais que são considerados adequados para a sociedade, por meio de contingências econômicas, políticas e sociais. Representadas pelo governo, leis e instituições, as agências controladoras têm como função estabelecer a manutenção desses comportamentos, bem como punir e coibir aqueles indesejáveis e socialmente inadequados.

A análise do controle evolui para outra interpretação quando se trata de problemas sociais: o autocontrole ético, o qual é definido por Borba, Tourinho e Glenn (2014) como o comportamento que produz respostas atrasadas em benefício da cultura, tanto para a geração atual como para as gerações subsequentes. Os autores salientam que o termo ético não implica juízo de valor, mas diz respeito a quem será beneficiário da resposta autocontrolada: as consequências de longo prazo têm muito mais chances de beneficiar as gerações futuras do que as atuais.

Outra contribuição da Análise do Comportamento na interpretação das práticas culturais e de suas consequências são os conceitos de macrocontingência e metacontingência. A primeira se refere às práticas circunscritas à repetição de comportamentos operantes individuais que, mesmo independentes entre si, ao serem tomados em conjunto produzem um efeito cumulativo que afeta todo o grupo (Malot \& Glenn, 2006).

Há outras situações em que o entrelaçamento de contingências comportamentais produzem resultados que dificilmente seriam alcançados isoladamente, como é o caso da metacontingência. Nas contingências comportamentais entrelaçadas, uma contingência funciona como estímulo antecedente ou consequente para o comportamento subsequente, e assim sucessivamente. O efeito destes entrelaçamentos é o produto agregado, avaliado e selecionado por um sistema receptor, e que aumentará a probabilidade de ocorrência das contingências comportamentais entrelaçadas. Assim, as práticas culturais são descritas por este conjunto formado pelo entrelaçamento de contingências, o produto agregado e a seleção do ambiente (Glenn, 2004).

A principal diferença entre ambas as unidades de análise é que na macrocontingência, diferentemente da metacontingência, não há a seleção cultural pelo sistema receptor, bem como não há a relação de dependência entre as contingências comportamentais. Na metacontingência, o entrelaçamento é 
importante para garantir a ocorrência, a manutenção e a transmissão das práticas culturais, enquanto que, na macrocontingência, é necessário o estabelecimento de regras que promovam a mudança nos comportamentos individuais das várias pessoas envolvidas em determinada prática cultural, a fim de mudar os seus efeitos cumulativos (Glenn, 2004). No caso de políticas públicas que objetivem a mudança de determinadas práticas, a tentativa de controle social dos comportamentos individuais seria inviável para resolver os efeitos cumulativos produzidos contra o grupo. Por isso, a metacontingência pode ser a unidade mais adequada para se programar mudanças de práticas culturais por meio da seleção de contingências comportamentais entrelaçadas e do produto agregado.

As considerações de Skinner, em sua obra Walden II, antecediam até mesmo os debates, em âmbito internacional, sobre educação ambiental, iniciados na década de 1970 e que orientaram a criação de uma agenda - para a resolução de problemas ambientais globais e de desenvolvimento sustentável como premissa a ser adotada por outros países (Gusso \& Sampaio, 2010). A realização das Conferências Mundiais sobre Desenvolvimento e Meio Ambiente foi - marco para os debates da época, quando se passou a discutir em âmbito mundial possíveis estratégias de como reordenar a economia visando ao bem comum e ao futuro sustentável. Este processo culminou na definição do conceito de Desenvolvimento Sustentável (World Commission on Environment and Development, 1987), que foi popularizado na Eco 92: o desenvolvimento que satisfaz as necessidades das gerações presentes sem comprometer a capacidade de as gerações futuras satisfazerem as suas próprias necessidades.

Os problemas ambientais seriam um exemplo de consequências que são prejudiciais para a espécie, mas que são produzidos individualmente pelos reforçadores estabelecidos pelo uso indiscriminado dos recursos naturais. $\mathrm{Na}$ mesma medida, o planejamento de práticas que visam aumentar a probabilidade de sobrevivência, em longo prazo, da cultura e do meio ambiente, depende de restrições da liberdade individual. Para isso, seriam necessárias duas condições, quais sejam: intervir em práticas culturais de modo a controlar as condutas prejudiciais e imediatistas e reforçar costumes favoráveis aos indivíduos e à cultura; e ensinar os indivíduos a aguardar as consequências positivas atrasadas que não necessariamente possuem fundamento para a sobrevivência imediata (Abib, 2001).

Nesse caso, a relação temporal entre resposta e consequência dá aos indivíduos a falsa ideia de que as práticas prejudiciais ao ecossistema, ao acontecerem na vida privada, terão efeitos mínimos, quando não, inofensivos. Ocorre que os efeitos dos padrões de utilização desenfreada dos recursos naturais, ao serem tomados como uma prática cultural, produzem resultados catastróficos de destruição ambiental que afetam toda a sociedade. Este é um exemplo da ausência de autocontrole ético: os indivíduos comportam-se de 
modo a obter reforçadores imediatos e em curto prazo, mas que no conjunto acumulado com outros comportamentos deste tipo, em longo prazo, produzem consequências sociais problemáticas.

Estudos experimentais, tais como o de Costa (2013) e Camargo (2014), buscaram subsidiar propostas de pesquisas e de intervenções destinadas às práticas culturais por meio do conceito de metacontingência associada aos recursos naturais. Um dos resultados indica que a organização de práticas culturais em macrocontingências e metacontingências podem facilitar a observação dos produtos agregados que são capazes de causar riscos e prejuízos para o grupo e o ambiente. Contudo, Camargo (2014) ressalva que estes resultados ainda são incipientes quanto ao estudo das formas de transmissão e manutenção, em longo prazo, das práticas culturais pautadas na sustentabilidade.

Outros conceitos também foram desenvolvidos para o estudo das práticas sustentáveis, em articulação com a Psicologia Ambiental e Cognitiva, como os comportamentos ambientais e pró-ambientais. Grosso modo, os primeiros se referem àqueles que promovem mudanças na disponibilidade de recursos ambientais ou que alteram a estrutura e as dinâmicas do ecossistema ou da biosfera. Já os comportamentos pró-ambientais, referem-se àqueles que beneficiam o meio ambiente ou que, pelo menos, causam o mínimo impacto possível (Steg \& Vlek, 2009). Morren e Gristein (2016) identificaram que esses estudos avançaram desde uma perspectiva experimental até uma análise mais cultural sobre os problemas ambientais, considerando que os comportamentos ambientais tanto são modelados pelas particularidades das culturas quanto pelo modo como os países competem, no contexto global, por recursos econômicos e naturais. Estes fatores podem servir ora para favorecer, ora para constranger práticas sustentáveis.

Os efeitos do incentivo financeiro nos estudos comportamentais

Maki, Burns, Ha e Rothman (2016) realizaram uma metanálise de estudos que investigaram os efeitos da intervenção do incentivo financeiro (monetário ou não) para o estabelecimento de comportamentos pró-ambientais como, por exemplo, reciclagem, utilização de transporte público e consumo racional de energia. De um total de 30 estudos selecionados, os autores identificaram que quando os incentivos foram concedidos e, logo em seguida, retirados, os seus efeitos foram de médio a baixo. No caso de experimentos em que se utilizou um intervalo variável, os efeitos na manutenção dos comportamentos foram maiores do que aqueles em que se utilizou um intervalo fixo para a distribuição dos incentivos, mas apenas quando o incentivo foi dado imediatamente. Além disso, os incentivos em dinheiro foram mais eficazes para os comportamentos de reciclagem, e os incentivos indiretos, como passagem de transporte, foram mais eficazes para a utilização de transporte público, assinalando-se a existência 
também de uma relação combinada entre o tipo de incentivo e o comportamento desejado. Entretanto, a manutenção desses comportamentos pode ser comprometida a partir da retirada dos incentivos.

Em geral, os resultados indicam que os incentivos financeiros podem promover a mudança comportamental favorável ao meio ambiente, bem como contribuir para a manutenção desses comportamentos em determinados contextos. Mas esses resultados podem ser limitados, no contexto social, pela formulação de políticas públicas não fundamentadas em diretrizes baseadas em evidências. A referência em pesquisas poderia favorecer os formuladores a selecionar recompensas mais adequadas aos tipos de comportamentos que são alvo das políticas públicas. Outra limitação apontada por Maki et al. (2016) diz respeito aos contextos nos quais os incentivos são implementados, no caso de ser públicos ou privados, o que pode afetar diretamente as decisões tomadas pelos indivíduos para se engajar em comportamentos pró-ambientais ou não. Esta variável foi, muitas vezes, negligenciada nos estudos levantados.

Compreender de que modo estes fatores atuam como mediadores dos comportamentos são fundamentais, do ponto de vista dos estudos, para o desenvolvimento de políticas públicas favoráveis ao avanço de práticas ambientais e sustentáveis. Corral-Verdugo e Pinheiro (1999) criticam a forma como os países, sobretudo os mais pobres, traduzem suas iniciativas em relação aos comportamentos pró-ambientais, muitas das quais desconsideram a gama de variáveis relacionadas à questão ambiental. Por isso, os autores defendem a necessidade de ir além deste combinado de ações, e convencer as agências de fomento e os agentes institucionais a investir em estudos nesta área a fim de que se possa, efetivamente, criar ferramentas necessárias para equalizar os efeitos da degradação ambiental, em nível local e global.

Pagamento por serviços ambientais (PSA): definições, inovações e limitações das recompensas financeiras para práticas de agricultura sustentáveis

Serviços ambientais são definidos como os benefícios recebidos do meio ambiente e dos ecossistemas em geral (Engel, Pagiola, \& Wunder, 2008). Levando-se em conta este conceito, bem como os argumentos do aumento populacional e os seus efeitos, pode-se afirmar que, na atualidade, a demanda por estes serviços tem aumentando de forma significativa. Partindo desta premissa, projetos relacionados ao Pagamento por Serviços Ambientais estão sendo implementados sob diversas modalidades, incluindo-se retribuições econômicas. Com relativa frequência, pessoas que vivem e trabalham no campo não recebem uma compensação equivalente aos serviços gerados - dos quais outros se beneficiam -, fato que está na base da criação de incentivos, visando dar certo equilíbrio a esta relação (Pagiola, Arcenas, \& Platais, 2004).

E como é possível interpretar os princípios das políticas ambientais que se utilizam de instrumentos econômicos, seja para recompensar comportamentos 
pró-ambientais, seja para coibir comportamentos que geram danos? Segundo Shiki, Shiki e Rosado (2015), o primeiro princípio refere-se aos instrumentos econômicos que geram um estímulo positivo para aqueles cujos comportamentos são pró-ambientais e que proporcionam benefícios comuns para a comunidade. 0 segundo refere-se aos instrumentos que funcionam como um estímulo negativo para os agentes que degradam o meio ambiente e que geram prejuízos para toda a sociedade como, por exemplo, a cobrança de taxas sobre emissão de gases, para os serviços de coleta de lixo, etc. Um terceiro princípio consiste na utilização do instrumento econômico como sistema de precaução, a favor da mudança comportamental que reduz a degradação ambiental. Neste caso, os comportamentos permaneceriam causando consequências negativas, mas a dimensão destes impactos é que seria minimizada por meio dos incentivos financeiros.

O PSA transfere recursos (monetários ou não) às pessoas físicas, às jurídicas ou a comunidades que contribuem para a manutenção dos ecossistemas naturais por meio de suas atividades econômicas. Quem recebe os pagamentos são aqueles que vivem em áreas relevantes para a manutenção dos serviços ambientais, como agricultores, empresas ou até mesmo o poder público. Os recursos são concedidos pela iniciativa privada ou pelo poder público, que aportam pagamentos para áreas que podem ser conservadas ou recuperadas, aliadas às atividades econômicas sustentáveis.

Um dos primeiros países latino-americanos a implantar o PSA foi a Costa Rica, em 1997, por meio da cobrança de uma taxa sobre o consumo da gasolina, tarifa esta destinada à proteção das florestas do país. México, Colômbia e El Salvador também implementaram políticas com lógicas e objetivos similares, mas apresentam algumas diferenças no que se refere aos processos de implantação (Pagiola et al., 2004). Tal como na maior parte dos países, no Brasil, o PSA tende a ser implantado em serviços de proteção dos recursos hídricos e em áreas de bacias hidrográficas.

A despeito dos esforços, os instrumentos coercivos de comando e controle existentes no país, tal como o Código Florestal, não têm sido eficientes para garantir o cumprimento da função social e ambiental da terra. Por conta desta falha, os PSA se justificariam, do ponto de vista dos governos, enquanto estratégia inovadora para suplantar este problema. Diferentemente de outras políticas ambientais, como o licenciamento ou cobranças de taxa sobre quem polui ou degrada, o PSA vai na contramão das práticas punitivas ao incentivar, financeiramente, que os agricultores adotem práticas mais sustentáveis (Foleto \& Leite, 2011).

Estudos realizados sobre a implantação de PSA em áreas de microbacias apontam que esta pode ser uma boa estratégia para garantir a prática da agricultura sustentável, pois influencia na gestão dos recursos hídricos e florestais em áreas de bacia hidrográfica. Mas a obtenção dos resultados 
pretendidos não depende apenas dos agricultores, mas também da colaboração dos governos locais (Jardim, 2011; Shiki et al., 2015). Por outro lado, o PSA pode ser menos compensador do que outros projetos que propiciam, mesmo sem o pagamento, condições para que os agricultores familiares possam fazer a transição para modelos alternativos de uso da terra (Costa, 2008).

Para Pagiola, von Glehn e Taffarello (2013), os pagamentos devem garantir um benefício adicional aos agricultores, pois, caso contrário, eles não mudarão o seu comportamento para adotar práticas mais sustentáveis de agricultura. Também o custo do serviço, para os pagadores, deve ser menor do que o valor do benefício obtido, pois, do contrário, eles não estariam dispostos a pagar por isto. Portanto, o PSA torna-se interessante à medida que gera novos financiamentos que não estariam disponíveis aos agricultores, que conserva serviços cujos benefícios vão além de seu custo, e que tem potencial para ser sustentável, pois dependeria apenas da relação voluntária entre prestador de serviço e pagador, e não da disponibilidade de financiamento do poder público. No Brasil, o poder público tem restrições em fazer pagamentos diretamente aos agricultores, sendo um dos principais obstáculos na execução de projetos de PSA. Shiki et al. (2015) rebatem esta afirmação asseverando que, no país, a maior parte dos projetos de PSA estão fora do circuito privado, além de se constituírem nas melhores experiências de PSA.

De todo modo, os estudos compartilham de opiniões semelhantes quanto aos limites e dificuldades existentes na implantação de projetos de PSA. Uma das maiores dificuldades identificadas refere-se à definição do valor a ser pago pelo serviço, pois as características territoriais e ambientais diferem-se de região para região. A análise do território é complexa, o que faz a avaliação ser sempre parcial. Isto impacta diretamente na relação do agricultor com o PSA pois, quanto mais o pagamento refletir a realidade do custo de oportunidade para o agricultor, mais ele estará motivado a aderir às práticas sustentáveis (Foleto \& Leite, 2011). Isto requer que os planejamentos dos projetos sejam adaptativos, uma vez que as decisões tomadas necessitam ser revistas constantemente em função das mudanças e do surgimento de novos conhecimentos sobre o território (Shiki et al., 2015).

Eloy, Coudel \& Toni (2013) apontam que as avaliações dos projetos de PSA tendem a ser analisadas, majoritariamente, pelas ciências econômicas em nível macro, negligenciando-se a complexidade dos arranjos sociais e institucionais relacionados às dinâmicas socioambientais dos territórios em que esses projetos são implantados. Para Muradian et al. (2010), este pode ser um problema de ordem conceitual, pois no campo do PSA há diferentes abordagens teórico-metodológicas que o caracterizam. Uma delas é a proposta do PSA ser estabelecido como uma relação comercial qualquer, desde que os custos de transações sejam baixos o suficiente e os direitos de propriedade claramente definidos. Assim, indivíduos, comunidades e mesmo instituições transnacionais 
podem comercializar os seus direitos por meio de recompensas pelos benefícios ambientais prestados. Os problemas ambientais passariam, então, não por uma solução de mudança comportamental, senão pela criação de mercados de serviços ambientais. O PSA, do ponto de vista da mercantilização ambiental, também deixa de reconhecer a variedade de contextos e ambientes institucionais nos quais operam os PSA.

Outra perspectiva compreende o PSA como uma transação voluntária, na qual um serviço ambiental é comprado de um prestador de serviços apenas se este garantir o seu provimento. Consequentemente, há pelo menos três condições para que este esquema "genuíno" de PSA seja estabelecido, a saber: a) a relação entre o tipo de terra e o serviço a ser prestado deve ser clara; b) os apoiadores devem ter a possibilidade de encerrar a relação contratual; e c) um sistema de monitoramento deve acompanhar a intervenção, a fim de garantir que a prestação de serviço está sendo realizada.

No entanto, Muradian et al. (2010) consideram que a maioria das experiências em PSA não contempla tais condições. Seja porque muitas iniciativas recebem pouco ou nenhum monitoramento, seja porque há casos em que os pagamentos são feitos antecipadamente à realização do serviço, sem estabelecer uma relação contingente entre o pagamento e o serviço prestado. Além disso, os autores identificaram que algumas formas de monitoramento focalizam apenas as mudanças em relação ao uso da terra, ao invés de verificarem as mudanças nos resultados do serviço ambiental prestado. Os estudos de viabilidade enfocam os resultados da implantação do ponto de vista econômico e da prática em si, mas não estabelecem a relação destes com os comportamentos dos agricultores; esta condição também é reproduzida nas experiências brasileiras, segundo Pagiola et al. (2013). O monitoramento geralmente é feito diretamente no campo, a fim de verificar o cumprimento dos contratos, bem como autorizar os pagamentos. A preocupação maior é conseguir detectar casos de não conformidade das condições contratuais, deixando em segundo plano os reais benefícios ambientais obtidos com o serviço.

Como o PSA contempla variadas estratégias de ação e um complexo arranjo institucional entre agentes públicos e privados, a implantação destes projetos depende fortemente do envolvimento destes atores e do engajamento da comunidade local, de tal modo que não podem ser considerados como uma simples transação voluntária de mercado (Muradian et al., 2010).

\section{MÉTODO}

Trata-se de um estudo descritivo qualitativo (Yin, 1994), cujo método pautou-se na combinação entre duas estratégias distintas e complementares de levantamento dos dados, quais sejam: 
(a) levantamento bibliográfico e documental sobre os conceitos relacionados à sustentabilidade, análise do comportamento, comportamentos pró-ambientais e aos estudos relacionados ao conceito e experiências de Pagamento por Serviços Ambientais;

(b) dados obtidos a partir de um estudo de caso sobre a implantação de um projeto de PSA por um grupo de 35 agricultores familiares de um assentamento rural localizado na região de Ribeirão Preto, Estado de São Paulo. O levantamento de informações aconteceu entre 2015 e 2016, deu-se por meio de observações diretas e de entrevistas semiestruturadas individuais com os participantes do projeto. Para analisar os dados, crivaram-se as diferentes fontes de informações que foram interpretadas a partir do referencial analíticocomportamental.

\section{RESULTADOS E DISCUSSÃO}

O PSA no Estado de São Paulo: apresentação e discussão do caso

O Estado de São Paulo tem lançado mão de estratégias de implantação de projetos ambientais em pequena escala, em territórios nos quais se caracteriza a produção familiar e a utilização de técnicas de agricultura menos extensivas e que respeitam o uso racionalizado dos recursos naturais, combinando a produção de alimentos com a conservação ambiental, como é o caso da agroecologia e dos sistemas agroflorestais (Safs). O Saf é uma técnica de consórcio de cultura agrícola que incorpora culturas anuais e espécies arbóreas que podem ser utilizadas para restaurar e recuperar áreas ambientalmente degradadas (Empresa Brasileira de Pesquisa Agropecuária, 2004). Do ponto de vista da Secretaria, esta abordagem facilita ao Estado obter maior controle sobre a experimentação e a implantação dos projetos, bem como de seus resultados, sendo também uma forma de, futuramente, convencer os grandes produtores a adotarem práticas de agricultura mais sustentáveis com base em evidências econômicas e empíricas.

O Projeto de Desenvolvimento Rural Sustentável (PDRS) Microbacias II é uma das estratégias recentes do Estado de São Paulo para a implementação de projetos de PSA, é executado pela Secretaria do Meio Ambiente (SMA) e pela Coordenadoria de Assistência Técnica Integral (CATI), com recursos do acordo de empréstimo firmado com o Banco Mundial, visando apoiar a sustentabilidade econômica, ambiental e social da agricultura familiar (von Glehn et al., 2012). Um dos objetivos do projeto é selecionar e apoiar propostas de implantação de sistemas agroflorestais que contribuam para adequação ambiental de áreas estratégicas, como as de microbacias hidrográficas, preferencialmente nas quais já haja em curso uma prática sustentável. 
O funcionamento do projeto acontece da seguinte forma: (1) a SMA lança o edital constando as regras para a seleção e financiamento de projetos ambientais de implantação de sistemas agroflorestais ou outras atividades agrícolas que promovam o manejo sustentável do solo e da água; (2) o grupo de agricultores, representado formalmente por uma cooperativa, associação ou ONG, elabora uma proposta de execução do projeto que deverá ser composta por, no mínimo, $70 \%$ de agricultores familiares. A organização apresenta um plano de ação para a aplicação dos recursos destinados à implantação dos sistemas agroflorestais e um cronograma de execução; (3) após a avaliação e seleção das propostas, a Secretaria firma um convênio, pelo período de dois anos, com as organizações que atenderam aos pré-requisitos exigidos de regularidade fiscal e de experiência com os sistemas agroflorestais; e (4) as áreas nas quais serão implantados os sistemas agroflorestais passam por uma avaliação ambiental que identificará os impactos ambientais das atividades consideradas e as medidas que potencializam seus impactos benéficos, e servirá como uma linha de base para o alcance dos objetivos propostos.

Dentre as regras estabelecidas em edital, o valor máximo dos recursos destinados para cada projeto selecionado é de $\mathrm{R} \$ 600.000,00$. Para receber o recurso, os agricultores precisam cumprir o compromisso de implantar áreas de sistemas agroflorestais com, no mínimo, $40 \%$ de árvores nativas regionais (que não poderão ser exploradas comercialmente), consorciadas com espécies agrícolas de cultivo anual, e que sejam mantidas por boas práticas de manejo do solo e das águas, mesmo após o término do recebimento dos recursos.

A recompensa pelo serviço não é monetária, isto é, não há recompensa direta por meio de repasse de dinheiro aos agricultores beneficiários. A destinação do pagamento acontece para a organização e deverá ser gerido coletivamente pelos beneficiários, devendo ser aplicado exclusivamente na compra de itens relacionados à execução do serviço ambiental: equipamentos de uso individual ou de uso coletivo, materiais de consumo, realização de obras em espaço físico para uso coletivo da organização, contratação de assistência técnica e cursos, mudas e substratos. Portanto, a compensação do projeto, embora não seja monetária, acontece tanto para o grupo - pois poderá viabilizar melhorias na infraestrutura e na gestão das organizações coletivas - quanto individualmente para cada agricultor, que receberá equipamentos, capacitações para a implantação e manejo do sistema agroflorestal, além das mudas que serão incorporadas ao seu lote.

Os recursos são liberados gradativamente, à medida que as etapas de implantação dos sistemas agroflorestais, previstas em cronograma, são atingidas. Uma equipe técnica da Secretaria é responsável por monitorar, periodicamente, as organizações por meio de instrumentos como relatórios de cada passo da implementação do programa, nos quais são registrados as 
dificuldades enfrentadas, possíveis desistências verificadas e o cumprimento das regras dispostas nos convênios.

Outra regra, neste caso, é que o grupo de agricultores beneficiados deve conceder uma contrapartida, que também não é monetária, mas é calculada com base no valor total concedido para a execução do projeto. Os agricultores deverão pagar $10 \%$ desse valor, por meio de sua mão de obra, para a implantação dos sistemas agroflorestais (São Paulo, 2013).

Depois da fase de implantação do Saf pelos agricultores e do recebimento dos recursos, o monitoramento do projeto prossegue observando-se dois indicadores: as mudanças ocorridas no uso da terra, por meio da manutenção do cultivo agrícola com boas práticas de manejo do solo e da água; e a ampliação do potencial de exploração econômica da produção familiar. Na fase de conclusão do convênio, as organizações executoras devem elaborar um relatório final sobre os objetivos alcançados, dificuldades enfrentadas e soluções implementadas.

No final de 2014, um grupo de 35 agricultores familiares assentados, representados por uma cooperativa, apresentou voluntariamente uma proposta de projeto ambiental que foi selecionado pelo PDRS: o de implantação de sistemas agroflorestais. As experiências de implantação do projeto, que serão descritas a seguir, foram observadas desde o início do convênio até agosto de 2016, e deverão seguir em curso até abril de 2017, quando termina o convênio firmado entre a cooperativa e a SMA.

A área geográfica do assentamento rural faz parte da bacia hidrográfica do Rio Pardo, além de estar sob área de recarga do Aquífero Guarani. Esta foi uma área que sofreu fortes impactos em função da monocultura da cana-de-açúcar (cultura agrícola predominante na região), e os antigos proprietários da área tinham uma grande dívida com o Estado por não cumprirem as leis ambientais. Como condição para que a área fosse destinada à reforma agrária, o Governo Federal e o Ministério Público determinaram aos agricultores a adoção da produção agroecológica a fim de recompor o ecossistema degradado e de proteger os recursos hídricos. Desde então, os agricultores possuem pelo menos 15 anos de experiências com a implantação de sistemas agroflorestais e uso da agroecologia como matriz produtiva. Esta experiência prévia com o uso de formas mais sustentáveis de agricultura foi uma das condições para a execução do projeto de PSA.

Para este grupo, o projeto estabeleceu a implantação do Saf em áreas entre 0,5 e 1,0 hectare por lote de agricultor, aproximadamente 30 hectares de área total. Para executarem o serviço em seus próprios lotes, os agricultores receberam equipamentos, insumos, sementes, mudas de árvores frutíferas e nativas e assistência técnica especializada. Para cada etapa de execução prevista no cronograma, a prestação de contas do período era realizada para que os recursos das etapas seguintes fossem liberados. Até o final do convênio, ainda será realizada a fase de monitoramento do projeto. Um consultor financeiro, 
escolhido pela SMA e pelo Banco Mundial, selecionará alguns lotes e os acompanhará durante nove meses, observando indicadores de viabilidade econômica do Saf e a evolução física e ambiental da área implantada. Os agricultores também deverão processar 20 toneladas de alimentos provenientes do Saf, sendo este um dos indicadores de viabilidade econômica do serviço prestado.

Na primeira etapa de implantação do projeto, os agricultores receberam equipamentos de uso individual (roçadeiras, enxadas, carriolas, facões), como um estímulo inicial ao grupo. Em um segundo momento, ocorreu a etapa de implantação dos Safs, que contou com as orientações de um serviço de assistência técnica que configurou o desenho de implantação do lote, respeitando as características de cada lote e as sugestões dos agricultores. Para a formação de mão de obra, grupos de mutirões foram organizados pelas famílias e por voluntários.

Como o pagamento pelo serviço prestado, neste caso, dependia diretamente do trabalho de cada agricultor, o Saf também significava maior uso da força física. Para determinadas técnicas de manejo do plantio, os agricultores precisavam dispensar o uso de maquinário e utilizar outros instrumentos que exigiam maior esforço físico. A idade já avançada da maioria dos agricultores e a falta de recursos financeiros para contratar mão de obra externa para executar o serviço eram problemas enfrentados pelos agricultores. Estas dificuldades não foram previstas no planejamento do projeto, cujo plano inicial considerava apenas possíveis alterações climáticas que poderiam influenciar em atrasos na execução do cronograma e na perda de plantios.

Assim que acabou a etapa de recebimento dos recursos sob forma de equipamentos e mudas, gradativamente os agricultores deixaram de participar das atividades coletivas relacionadas à gestão do projeto, como reuniões e assembleias. Era comum os agricultores relatarem sobre o desânimo em permanecer manejando a área do Saf após o término do convênio - previsto para abril de 2017 - ou até mesmo se referirem à área implantada como se esta não fizesse parte do próprio lote. Caso houvesse desistência por parte do agricultor em permanecer no projeto, a SMA aceitaria a redução de, no máximo, $50 \%$ do número de agricultores que aderiram ao projeto. Mas isto apenas se pelo menos $75 \%$ das etapas de implantação tivessem sido realizadas, e se bem justificado. Caso contrário, o agricultor deveria devolver todo o recurso recebido, desta vez, na forma monetária. Apesar do desânimo, nenhum agricultor desistiu.

As condições para a implantação do Saf extrapolavam a simples condicionalidade entre a prestação do serviço controlado e o pagamento recebido por ele. Além da relação estabelecida entre os recursos recebidos e a implantação dos sistemas agroflorestais, assim como nos casos relatados pela literatura, a execução do projeto dependeu de um arranjo complexo entre os agricultores, no cotidiano de trabalho, e destes com as instituições. Embora 
formalizadas, as regras nem sempre foram claras o suficiente para definir a interdependência entre os comportamentos individuais e grupais a fim de se alcançar os resultados esperados, como também não foram observadas outras contingências que poderiam interferir no efeito de manutenção das práticas sustentáveis.

Resultados preliminares do projeto

Foi possível notar, nas diferentes etapas programadas para a execução do projeto, que a mudança comportamental desejada se referia ao comportamento operante individual do agricultor (macrocontingência), objetivando a substituição das práticas de agricultura convencional pela sustentável, por meio da implantação de sistemas agroflorestais. Mas, esta condição dependia de uma configuração mais ampla e de articulação entre as contingências comportamentais do grupo (metacontingências).

Ainda que a implantação dos Safs ocorresse de modo individualizado, o convênio com a instituição pagadora foi firmado por uma organização coletiva representante dos agricultores, que também eram responsáveis, coletivamente, pela gestão e execução do projeto.

Os resultados previstos não seriam atingidos por um único comportamento e, portanto, dependiam do engajamento do grupo para tomar decisões e atender às condições iniciais que, por sua vez, serviam de ambiente para a consecução das etapas seguintes de implantação do projeto. O ambiente selecionador deste entrelaçamento de comportamentos tanto era formado pelas agências pagadoras do serviço, quanto pela comunidade que se beneficiaria dos resultados de conservação dos recursos naturais proporcionados pelo produto agregado dos sistemas agroflorestais. Esta característica do projeto era considerada importante pelos agentes governamentais pois poderia favorecer a permanência do engajamento do grupo em tomadas de decisões coletivas para a resolução de outros problemas do cotidiano, além da permanência de práticas sustentáveis de agricultura.

Mas, como a seleção - ou não - de algumas práticas pode depender, ainda, da competição entre pessoas ou culturas e de limites estruturais nos níveis de seleção (Skinner, 1981), outras contingências também competiam para a ameaça de continuidade das práticas de agricultura sustentáveis após o final do projeto. Mesmo após 15 anos de experiências com os sistemas agroflorestais, a agroecologia ainda não havia sido incorporada plenamente pelos agricultores desse projeto. Havia uma série de problemas que limitavam seu uso, a exemplo dos preços dos insumos orgânicos que, em comparação com os insumos convencionais, são muito maiores. Além disso, a rede para captação de água para o plantio era deficitária e insuficiente para atender a todas as famílias, havendo inúmeros problemas de abastecimento. 
Assim, existia uma forte concorrência entre as consequências de curto prazo do uso da agricultura tradicional e agroecológica, que é um modelo que demanda tempo, tanto para recompor o solo e tornar-se economicamente viável, quanto para ser aprendido. Por se tratar de um conhecimento científico que ainda estava em construção, os agricultores tinham muitas dúvidas em relação às técnicas necessárias para o seu manejo. Contribuiu também o fato de que muitos agricultores construíram seu repertório de trabalho rural no modelo de agricultura convencional e aprenderam com as gerações anteriores técnicas de plantio e de manejo distintos da agroecologia. A utilização de defensivos químicos, por exemplo, eram saídas conhecidas e desempenhadas pelos mesmos agricultores em muitas ocasiões pois, em curto prazo, resolviam problemas das culturas agrícolas que as técnicas agroecológicas levavam mais tempo para solucionar.

Os consumidores, enquanto ambiente cultural receptor e selecionador, também não atuavam como reforçador dos comportamentos sustentáveis dos agricultores. Na sociedade atual, há uma forte tendência de valorização, inclusive nos grandes centros urbanos, do consumo de alimentos livres de agrotóxicos orgânicos e agroecológicos, não só porque tem se debatido cada vez mais os impactos ambientais do modelo de agricultura convencional, como também devido às consequências do consumo desses alimentos para a saúde da população. Apesar disso, este é um processo ainda recente e restrito a um considerável "mercado de luxo", do qual a maioria da população ainda permanece excluída. Não por acaso, além de ser mais barato, o alimento produzido com agrotóxico (que aparenta ter maior qualidade estética) ainda é preferido pela maioria dos consumidores se comparado ao alimento agroecológico esteticamente inferior, a despeito de todos os benefícios que pode proporcionar, em longo prazo, para a saúde e para o meio ambiente.

Apesar dos problemas enfrentados, o projeto observado teve, até o momento, uma repercussão positiva entre os agricultores, que enfrentavam dificuldades para acessar linhas de créditos para o financiamento da produção. Como as políticas públicas previstas para criar a infraestrutura do território não foram implantadas totalmente, os benefícios econômicos condicionados ao projeto serviram como um importante estímulo inicial para que os agricultores recuperassem, pelo menos em curto prazo, as práticas agroecológicas que já haviam sido, em parte, abandonadas ao longo do tempo.

Por outro lado, é preciso reconhecer o risco de estes comportamentos não se manterem com o término dos pagamentos por meio de recompensas indiretas, ou ainda, de os comportamentos não se transformarem em práticas culturais. Na sociedade brasileira, as práticas sustentáveis de agricultura ainda são menos recompensadoras, em curto prazo, do que a agricultura convencional. No caso relatado, havia indícios de que este problema era ainda mais complexo, tanto porque não havia condições estruturais para os agricultores produzirem 
sustentavelmente (não houve o planejamento de políticas públicas que garantissem condições mínimas para que o comportamento agroecológico se tornasse vantajoso), quanto porque se tratava de recompensas em longo prazo, que concorriam com as necessidades imediatas de composição de renda das famílias.

Para a formulação de políticas públicas de desenvolvimento rural sustentável, é necessário considerar este conjunto de variáveis e de efeitos acumulados nas culturas das comunidades às quais se destinam, por exemplo a valorização da agricultura convencional e da monocultura como os padrões de produção agrícola selecionados pela cultura. Especialmente no contexto brasileiro, que sofre um processo de reprimarização da economia que depende, majoritariamente, da produção e da exportação da agricultura em larga escala. Por isso, em curto prazo, as consequências financeiras geradas por este setor são reforçadoras, mas, na mesma proporção, também são os danos causados ao meio ambiente em longo prazo. Daí também parte a dificuldade de a agricultura sustentável disputar espaço no mercado e estabelecer-se economicamente.

Apesar de todas as limitações enfrentadas pelos agricultores na implantação dos sistemas agroflorestais, as instituições que desempenham o papel de agências controladoras do projeto (Banco Mundial e Secretaria do Meio Ambiente) projetam os impactos criados com o programa com base em indicadores quantitativos e generalizados (aumento de até $8 \%$ nos valores de venda para as organizações e 0,4 mil hectares de área agrícola com melhores práticas de manejo de solo em todo o Estado de São Paulo). A dimensão comportamental, fundamental para a manutenção das práticas ambientais, não aparece como indicador. Por isso, corrobora-se as opiniões dos estudos que defendem a necessidade de haver maior flexibilidade para o planejamento, execução e monitoramento das etapas de implantação do projeto, e que estas passem a considerar, na fase de avaliação e revisão, questões imprevistas, tais como, por exemplo, a idade avançada dos agricultores, a falta de infraestrutura básica, de recursos econômicos e as dificuldades para se realizar determinadas atividades de manejo florestal.

Muradian et al. (2008) defendem a necessidade de os projetos de PSA se tornarem, na arena política, um mecanismo de relação ganha-ganha, tanto para a proteção do meio ambiente quanto para o alívio das condições de pobreza dos agricultores. Os agentes institucionais, especialmente aqueles de países em desenvolvimento, constantemente se deparam com a necessidade de atender a estes dois objetivos simultaneamente e não podem desconsiderar a equidade e justiça como fatores determinantes para desenhar as iniciativas de PSA. Os autores argumentam que há, na prática, um entrelaçamento entre eficiência e equidade, e os agentes institucionais irão, cada vez mais, deparar-se com os desafios de estabelecer a correlação entre os esquemas de PSA e os programas de desenvolvimento da população rural. Portanto, uma abordagem de PSA que 
priorize apenas os objetivos de eficiência econômica e deixe em segundo plano os problemas sociais, será limitada e inútil.

Pensando nas políticas públicas em termos de metacontingências e macrocontingências, estas ações precisariam levar em consideração não apenas o conjunto de comportamentos individuais de uso indiscriminado dos recursos naturais pela agricultura convencional e os efeitos acumulados desta prática. Ainda que suas consequências já estejam repercutindo na sociedade, seus efeitos mais profundos não chegarão a ser sentidos pela atual geração. Preencher esta lacuna entre consequências de curto e de longo prazo requer o planejamento e o controle destes comportamentos por meio de regras que sinalizem a organização de contingências comportamentais entrelaçadas, a fim de modificar as práticas culturais e o repertório comportamental dos indivíduos (Glenn, 2004).

\section{CONSIDERAÇÕES FINAIS}

Mesmo que o objetivo de projetos baseados em PSA seja obter efeitos controlados sobre a conservação dos recursos naturais por intermédio de práticas de agricultura sustentável, é possível observar - por meio da literatura e do caso relatado - que a recompensa não monetária, apesar de ser, em curto prazo, um importante reforçador para os agricultores, ainda é uma estratégia incipiente para garantir, em determinados contextos, que estas práticas permaneçam no repertório comportamental dos agricultores ou que sejam transformadas em práticas culturais transmitidas ao longo das gerações.

No caso relatado, embora a valorização financeira de uma prática sustentável de agricultura tenha sido importante para estimular o resgate e a manutenção destes comportamentos no período de dois anos, havia um contexto, emergencial, de manutenção da economia doméstica das famílias, que dependiam da produção e da comercialização de alimentos. Mesmo sob efeito das recompensas, os comportamentos corriam o risco de cessarem rapidamente em função de um complexo conjunto de condições de incertezas que competiam com a ocorrência das práticas de agricultura sustentável.

Além disso, conforme sugerido pela literatura, alguns projetos de PSA objetivam a criação de um mercado de serviços ambientais que, não necessariamente, pretende estabelecer a manutenção de práticas culturais sustentáveis em longo prazo, apostando que a recompensa financeira é suficiente para que tais projetos aconteçam no presente.

O PSA é uma estratégia interessante que visa romper com o padrão de controle aversivo e punitivo comumente exercido pelas agências governamentais para suprimir ou alterar determinados comportamentos da população. Os formuladores destes projetos não podem desconsiderar que estes exigem uma complexa arquitetura institucional que precisa estar alinhada às políticas de desenvolvimento rural para que se atinja as mudanças desejadas, quais sejam, a 
conservação ambiental e a prática da agricultura sustentável. Por isso, não podem prescindir de um planejamento comportamental e estrutural, de modo a garantir as condições concretas aos agricultores para que o desempenho da agricultura sustentável seja vantajoso em curto e longo prazo e, no futuro, possam se tornar uma prática cultural transmitida desta para as próximas gerações.

\section{REFERÊNCIAS}

Abib, J. A. D. (2001). Teoria moral de Skinner e desenvolvimento humano. Psicologia: Reflexão e Crítica, 14(1), 107-117. doi:10.1590/S010279722001000100009

Borba, A., Tourinho E. Z., \& Glenn S. (2014). Establishing the macrobehavior of ethical self-control in an arrangement of macrocontigencies in two microcultures. Behavior and social issues, 23, 68-86. doi: 10.5210/bsi.v.23i0.5354

Camargo, J. C. (2014). Desenvolvimento Sustentável: Uma Análise Experimental do Comportamento de Extração de Recursos em Microssociedades de Laboratório. Dissertação de Mestrado, Programa de Pós-Graduação em Análise do Comportamento, Universidade Estadual de Londrina, Londrina.

Corral-Verdugo, V., \& Pinheiro, J. Q. (1999). Condições para o estudo do comportamento pró-ambiental. Estudos de Psicologia, 4(1), 7-22. doi:10.1590/S1413-294X1999000100002

Costa, D. C. (2013). Metacontingências no uso de recursos naturais: O ambiente natural com pescadores e o laboratório com o Jogo Dilema dos Comuns. Tese de Doutorado, Instituto de Psicologia, Universidade de Brasília, Brasília.

Costa, R. C. (2008) Pagamento por serviços ambientais: Limites e oportunidades para o desenvolvimento sustentável da agricultura familiar na Amazônia Brasileira. Tese de Doutorado, Programa de Pós-Graduação em Ciência Ambiental, Universidade de São Paulo, São Paulo.

Empresa Brasileira de Pesquisa Agropecuária [Embrapa]. (2004). Sistemas Agroflorestais (SAFs). Recuperado de https://www.embrapa.br/busca-deprodutos-processos-e-servicos/-/produto-servico/112/sistemasagroflorestais-safs.

Engel, S., Pagiola, A., \& Wunder, S. (2008). Designing payments for environmental services in theory and practice: An overview of the issues. Ecological Economics, 65(4), 663-674. doi:10.1016/j.ecolecon.2008.03.011

Eloy, L., Coudel, E., \& Toni, F. (2013). Implementando Pagamentos por Serviços Ambientais no Brasil: caminhos para uma reflexão crítica. Sustentabilidade em Debate, 4(1), 21-42. doi:10.18472/SustDeb.v4n1.2013.9198 
Food and Agriculture Organization of the United Nations [FAO]. (2014). The State of Food and Agriculture. Innovation in family farming. Rome, IT: FAO.

Foleto, E. M., \& Leite, M. B. (2011). Perspectivas do Pagamento por Serviços Ambientais e exemplos de caso no Brasil. REA - Revista de estudos ambientais (Online), 13(1), 6-17. doi:10.7867/1983-1501.2011v13n1p6-17

Glenn, S. S. (2004). Individual behavior, culture and social change. The Behavior Analyst, 27(2), 133-151.

Gusso, H. L., \& Sampaio, A. A. S. (2011). Sustentabilidade e aquecimento global: A análise do comportamento pode ajudar? Boletim Contexto, (34), 10-19.

Hanna, E. S. \& Todorov, J. C. (2002). Modelos de autocontrole na análise experimental do comportamento: utilidade e crítica. Psicologia: Teoria e pesquisa, 18(3), 337-343. doi:10.1590/S0102-37722002000300014

Holpert, E. C. (2004). Questões Sociais na Análise do Comportamento. Revista Brasileira de Terapia Comportamental e Cognitiva, 6(1), 1-16.

Jardim, M. H. (2010). Pagamentos por serviços ambientais na gestão de recursos hídricos: o caso do município de Extrema. Dissertação de Mestrado, Programa de Pós-Graduação em Desenvolvimento Sustentável, Universidade de Brasília, Brasília.

Maki, A., Burns, R. J., Ha, L., \& Rothman, A. J. (2016). Paying people to protect the environment: A meta-analysis of financial incentive interventions to promote proenvironmental behaviors. Journal of Environmental Psychology, 47, 242 - 255. doi:10.1016/j.jenvp.2016.07.006

Malott, M. E., \& Glenn, S. S. (2006). Targets of intervention in cultural and behavioral change. Behavior and Social Issues, 15, 31-56. doi: 10.5210/bsi.v15i1.344

Medeiros, D. M. S., \& Haydu, V. B. (2013). Comportamento, educação ambiental e $o$ caso do Passeio das Bacias. Recuperado de http://www.uel.br/pessoal/haydu/textos/educacao_ambiental_e_o_caso_do _passeio_das_bacias.pdf

Morren, M, \& Gristein, A. (2016). Explaining environmental behavior across borders: A meta-analysis. Journal of Environmental Psychology, 47, 91106. doi:10.1016/j.jenvp.2016.05.003

Muradian, R., Corbera, E., Pascual, U., Kosoy, N. \& May, P. H. (2010). Reconciling theory and practice: An alternative conceptual framework for understanding payments for environmental services. Ecological Economics, 69, 1202-1208. doi: http://dx.doi.org/10.1016/j.ecolecon.2009.11.006

Pagiola, S., Arcenas, A. \& Platais, G. (2005). Can Payments for Environmental Services Help Reduce Poverty? An Exploration of the Issues and the Evidence to Date from Latin America. World Development, 33(2), 237-253. doi:http://dx.doi.org/10.1016/j.worlddev.2004.07.011 
Pagiola, S., \& Platais, G. (2002). Payments for Environmental Services. Environment Strategy Notes, (3), 1-4.

Pagiola, S., von Glehn, H. C., \& Taffarello, D. (2013). Experiências de Pagamentos por Serviços Ambientais no Brasil. São Paulo, SP: SMA/CBRN.

Sampaio, A. A. S., \& Andery, M. A. P. A. (2010). Comportamento Social, Produção Agregada e Prática Cultural: uma Análise Comportamental de Fenômenos Sociais. Psicologia: Teoria e Pesquisa, 26 (1), 183-192. doi: $10.1590 /$ S0102-37722010000100020

São Paulo (2013). Projeto de Desenvolvimento Rural Sustentável Microbacias II Acesso ao Mercado. Subcomponente 2.3 - Sustentabilidade Ambiental Atividade: Subprojetos Ambientais. Recuperado de http://sigam.ambiente.sp.gov.br/sigam3/Repositorio/476/Documentos/Edit al_SMA_Chamada_PDRS_SA_02.pdf

Skinner, B. F. (1972). Walden II. Uma sociedade do futuro. (R. Moreno \& N. R. Saraiva Trad.), São Paulo, SP: Herder. (Trabalho original publicado em 1948).

Skinner, B. F. (1979). Ciência e comportamento humano. São Paulo, SP: Martins Fontes. (Trabalho original publicado em 1953).

Skinner, B. F. (1981). Seleção por consequências. Revista Brasileira de Terapia Comportamental e Cognitiva, 9(1), 129-137. Recuperado de http://www.usp.br/rbtcc/index.php/RBTCC/article/view/150/133

Steg, L., \& Vlek, C. (2009). Encouraging pro-environmental behaviour: An integrative review and research agenda. Journal of Environmental Psychology, 29 (3), 309-327. doi:10.1016/j.jenvp.2008.10.004

Shiki, S., Shiki, S. F. N., \& Rosado, P. L. (2015). Políticas de pagamento por serviços ambientais no Brasil: avanços, limites e desafios. In S. Schneider \& C. Grisa, Políticas públicas de desenvolvimento rural no Brasil (pp. 281310). Porto Alegre, RS: Editora da UFRGS.

Tourinho, E. Z. \& Vichi, C. (2012). Behavioral- analytic research of cultural selection and the complexity of cultural phenomena. Revista Latinoamericana de Psicología, 44(1), 169-179. doi:http://dx.doi.org/10.14349/rlp.v44i1.942

von Glehn, H. C., Tafarello, D., Kamyiama, A, Dalla Vechia, A. C., \& Cogueto, C. V. (2012). O Projeto Mina d'Água em São Paulo, Brasil. PES Learning Paper, 1-19.

World Comission on Environment and Development (1987). Report of the World Commission on Environment and Development: Our Common Future. Genebra, $\mathrm{CH}$ : United Nations.

Yin, R. (1994). Estudo de caso: planejamento e métodos. Porto Alegre, RS: Artmed. 
Sobre as autoras

Thainara Granero de Melo é psicóloga pela Universidade Estadual de Maringá (UEM), mestre em Psicologia pela Universidade Federal de São Carlos (UFSCar) e doutoranda pela mesma instituição. thainaragm@gmail.com

Diana Catherin Mercado González é psicóloga pela Universidad de Antioquia (UdeA) e mestranda em Psicologia pela Universidade Federal de São Carlos (UFSCar). dianamercado90@gmail.com

Recebido em: 16/08/2016

Revisado em: 19/10/2016

Aceito em: 05/12/2016 